\title{
LESSON STUDY PADA PEMBELAJARAN MATEMATIKA BERBASIS APLIKASI
}

\author{
Edi Kurniadi \\ Departemen Matematika FMIPA Unpad \\ Jl. Raya Bandung Sumedang Km 21 Jatinangor Sumedang Jawa Barat, Indonesia 45361 \\ edi.kurniadi@unpad.ac.id
}

\begin{abstract}
In this paper we give a simple simulation to understand the concept of mathematics. We deliver two concept. First, how to understand the square area and the second is how to understand a finite summation of integers. By using lesson study, we design a method to improve the interest of students in this mathematics concept and to encourage a collaboration activity between students and teachers. After students have a good knowledge in mathematics concept, we present some problems in a smart phone application. The goal is to discuss various approaches and solutions.
\end{abstract}

Keywords: Applications, Lesson study, Square, Integers.

\begin{abstract}
Abstrak
Dalam artikel ini, diberikan sebuah simulasi sederhana bagaimana memahami konsep matematika yang baik dan benar. Pertama, bagaimana cara memahami luas sebuah lingkaran dan yang ke dua bagaimana cara memahami penjumlahan hingga bilangan bulat. Dengan menggunakan metode lesson study, didesain sebuah metode untuk menarik minat para siswa dalam memahami konsep matematika dan mendorong adanya kolaborasi antara para siswa dan guru. Setelah mempunyai pengetahuan yang baik dalam memahami konsep matematika, para siswa dibimbing untuk menyelesaikan soal-soal (problems solving) dari dua tema di atas dengan menggunakan aplikasi dalam ponsel pintar. Tujuannya adalah untuk melakukan berbagai pendekatan dalam penyelesaian soal-soal dan kemudian mendiskusikannya untuk mendapatkan jawaban terbaik.
\end{abstract}

Kata kunci : Aplikasi, Bilangan bulat, Lingkaran, Lesson study.

\section{PENDAHULUAN}

Belajar matematika dengan menggunakan aplikasi pembelajaran pada ponsel pintar adalah suatu modal dasar yang dapat digunakan untuk menarik minat belajar siswa. Terdapat banyak sekali aplikasi yang tersedia dalam Google Play Store baik yang berbayar atau yang gratis, seperti Ruangguru, Belajar Matematika, Game matematika, dan lain-lain. Aplikasi-aplikasi tersebut banyak menawarkan keunggulan-keunggulan yang menarik seperti rumus matematika praktis, panduan video untuk memperjelas konsep pembelajaran, bahkan ada juga yang diselingi dengan permainan-permainan sehingga proses belajar menjadi asik dan menyenangkan.

Berbagai kajian telah banyak dilakukan sebagai upaya untuk meningkatkan minat belajar matematika para siswa seperti analisis kesulitan siswa ditinjau dalam berbagai aspek seperti analisis kesulitan siswa SMP dalam menyelesaikan soal cerita persamaan linear (Puspitasari \& Nursangaji, 2015), analisis siswa SMP dalam kemampuan statistika ( Khadijah, dkk, 2018), analisis hubungan resiliensi kemampuan siswa dalam konsep lingkaran (Maharani \& Bernard, 2018), dan analisis kemampuan matematika siswa ditinjau dari gender (Sudirman, dkk, 2019).

Terlepas dari itu semua, proses pembelajaran matematika yang baik tentunya harus melibatkan keaktifan siswa itu sendiri agar materi atau konsep yang disampaikan dapat dipahami dengan baik dan benar (Brown, 1994) dan tentu saja rasa percaya diri siswa dalam mengerjakan soal 
matematika mempunyai peran yang sangat penting (Islamiah, dkk, 2018). Salah satu pendekatan yang dapat digunakan untuk meningkatan ketertarikan siswa dalam pembelajaran matematika adalah melalui Lesson study. Lesson study ini adalah suatu pengembangan pembelajaran secara profesional yang telah disampaikan secara meluas di Jepang (Fernandez, Chokshi, Cannon, \& Yoshida, 2001). Lebih jauh tentang Lesson study ini bisa dilihat dalam (Takahashi, 2006) dan (Takahashi, 2000).

Kunci dalam Lesson study ini adalah kolaborasi antara guru dan siswa untuk mencapai empat hal berikut ini (Murata\&Takahashi, 2002):

1. memformulasikan tujuan pembelajaran dan pengembangannya,

2. merencanakan, menyampaikan, dan mengobservasi,

3. mengamati dengan seksama proses pembelajaran yang berpusat pada siswa (student learning) selama proses pembelajaran serta menyimpulkannya, dan

4. mendiskusikan dan memperbaiki pelajaran dan pendekatannya berdasarkan pengamatan yang sudah dilakukan.

Sebagai contoh, diberikan dua rumus matematika sederhana berikut ini:

$$
\begin{aligned}
& x^{2}+y^{2} . \\
& (x+y)^{2} .
\end{aligned}
$$

Pertama, diharapkan para siswa dapat memaknai kedua rumus tersebut, dan guru dapat menyampaikan, mengobservasi, meneliti keaktifan para siswa, dan memperbaiki konsep yang kurang tepat dari para siswa terhadap pemahaman kedua rumus tersebut. Lebih lanjut, terhadap Rumus (1), mungkin saja para siswa bisa mengeja dengan mengatakan " $x$ kuadrat ditambah $y$ kuadrat" dan terhadap Rumus (2) mereka mengatakan "dalam kurung $x$ ditambah $y$ kuadrat". Padahal yang sebenarnya, para siswa diharapkan bisa menafsirkan Rumus (1) dengan mengatakan "jumlah kuadrat $x$ dan $y$ " dan terhadap Rumus (2) "kuadrat jumlah dari $x$ dan $y$ ". Tentu saja konsep dasar seperti ini perlu ditanamkan sejak dini agar konsep matematika dapat dipahami dengan baik dan benar.

Berpijak dari contoh sederhana di atas, dalam artikel ini akan diterapkan metode Lesson study dalam pembelajaran matematika berbasis aplikasi. Dua topik penting dalam artikel ini adalah memahami luas sebuah lingkaran dan penjumlahan bilangan bulat. Sebelum membahas soal-soal dalam aplikasi ponsel pintar, para guru akan mengajarkan terlebih dahulu konsep lingkaran dan penjumlahan bilangan bulat dengan simulasi sederhana.

\section{METODE PENELITIAN}

Jenis penelitian yang digunakan adalah deskriptif kualitatif yang bertujuan untuk menggambarkan atau mendeskripsikan kemampuan para siswa terhadap pemahaman konsep matematika khususnya tentang luas lingkaran dan penjumlahan hingga bilangan bulat positif.Subjek 
dari penelitian ini adalah siswa-siswa kelas VIII dan IX SMP Y di Jatinangor Kabupaten Sumedang Jawa Barat. Instrumen pengambilan dan analisis data yang dilakukan yaitu dengan memberikan soal latihan, kemudian mengamati, mendiskusikan rencana, menyimulasikan, mendiskusikan hasil, dan menarik kesimpulan dengan berbasis pada keaktifan siswa.

\section{HASIL}

Sebagaimana telah dijelaskan di atas bahwa Lesson study mencakup empat hal (Murata\&Takahashi, 2002) mulai dari perumusan tujuan pembelajaran dan pengembangannya sampai dengan evaluasi pembelajaran berdasarkan pengamatan yang dilakukan. Dalam artikel ini akan dibahas dua topik yaitu luas suatu lingkaran dan penjumlahan bilangan bulat.

Pemahaman para siswa terhadap konsep luas lingkaran dan penjumlahan hingga bilangan bulat dilakukan melalui problem solving yaitu dengan menyelesaian soal-soal yang berkaitan dengan topik yang diberikan. Problem solving ini bisa menciptakan ketertarikan siswa dalam matematika dan menstimulasi kekreatifan siswa dalam bermatematika (Lester\&Gorofalo, 1982). Fokus dalam pembelajarannya berpusat pada siswa (student learning center) melalui pembimbingan. Tentunya, perlu adanya peran aktif baik dari siswa maupun guru.

Topik pertama yang akan dibahas adalah luas sebuah lingkaran. Tujuannya adalah untuk menanamkan konsep dalam memahami luas lingkaran dengan melakukan simulasi sederhana, kemudian merencanakan, dan merancang model pembalajaran sederhana untuk diobservasi oleh para siswa dan guru. Selanjutnya adalah realisasi pengamatan dari model yang telah dibuat para siswa untuk mendapatkan hasil yang telah ditargetkan. Melalui diskusi hasil-hasil dari berbagai kelompok akan didiskusikan dan diperbaiki jika masih ada yang belum paham.

Para siswa diajak untuk bisa menemukan atau merumuskan sendiri luas sebuah lingkaran. Pertama, diasumsikan sebelumnya bahwa para siswa sudah memahami konsep luas persegi panjang, yaitu panjang kali lebar.

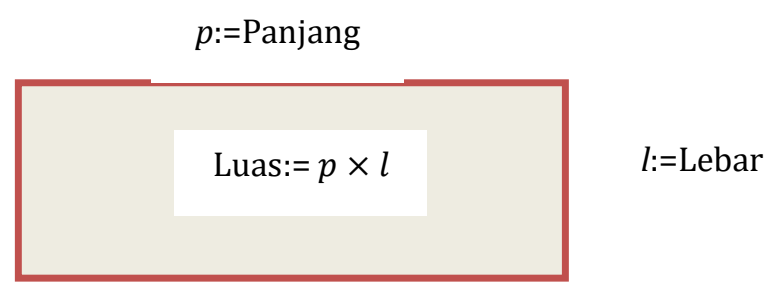

Gambar 1. Luas Persegi panjang

Langkah selanjutnya, para siswa menceritakan benda-benda yang sudah pernah mereka lihat yang ada hubungannya dengan lingkaran. Dalam hal ini, guru memberikan ilustrasi visual seperti di bawah ini. 


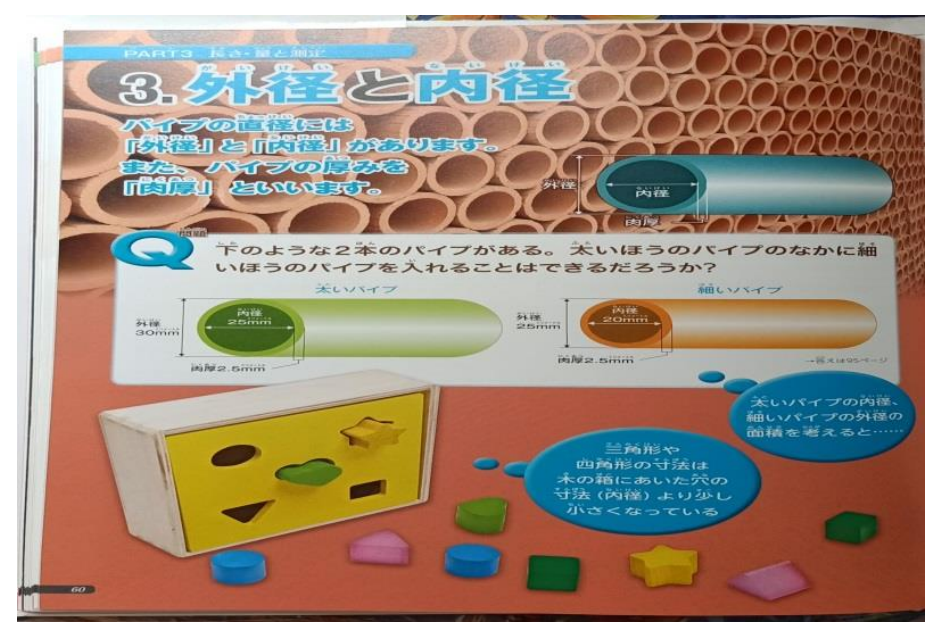

Gambar 2. Contoh benda yang memuat lingkaran (Yoshinori, Shimizu et al., 2015)

Setelah paham dengan contoh-contoh benda yang berhubungan dengan lingkaran, kemudian para siswa mengobservasi dan sekaligus mempraktikkan apa yang mereka pahami dari gambar berikut ini.

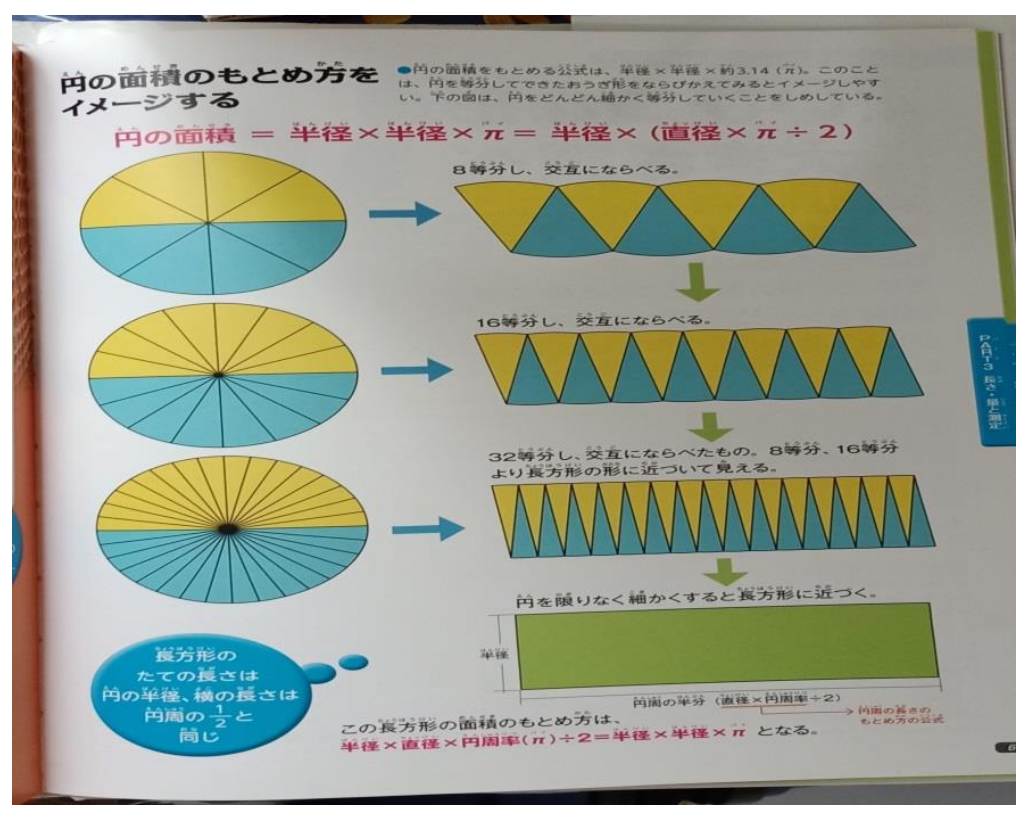

Gambar 3. Proses penentuan luas lingkaran(Yoshinori, Shimizu et al., 2015)

Para siswa membuat beberapa lingkaran dari karton yang dipartisi menjadi beberapa bagian kemudian hasil partisi tersebut digunting untuk kemudian diubah menjadi bentuk persegi panjang seperti dalam Gambar 3.2. di atas. Para siswa mengamati bahwa panjang dan lebar dari persegi panjang tersebut berturut-turut adalah $\pi r$ dan $r$ dengan $r$ adalah jari-jari lingkaran dan $\pi:=\frac{22}{7} \approx 3,14$. Pada akhirnya, dengan menggunakan luas persegi panjang, para siswa mendapatkan luas lingkaran sebagai berikut

$$
\pi r \times r=\pi r^{2} .
$$


Guru atau pendamping menjelaskan proses yang dilakukan oleh siswa dan membantu para siswa untuk memahami bagaimana mendapatkan luas lingkaran tersebut dan meyakinkan para siswa bahwa proses dan kesimpulan yang diambil adalah benar. Proses ini dapat dilakukan berulang kali sampai para siswa benar-benar paham tentang konsep luas lingkaran.

Langkah selanjutnya, setelah konsep luas lingkaran benar-benar dipahami, adalah problem solving dengan menggunakan soal-soal dalam aplikasi dari ponsel pintar para siswa. Variasi soal-soal yang diberikan akan mematangkan konsep luas lingkaran yang sudah diberikan sebelumnya. Berikut adalah beberapa contoh aplikasi matematika yang bisa digunakan dalam pemahaman konsep luas lingkaran tersebut
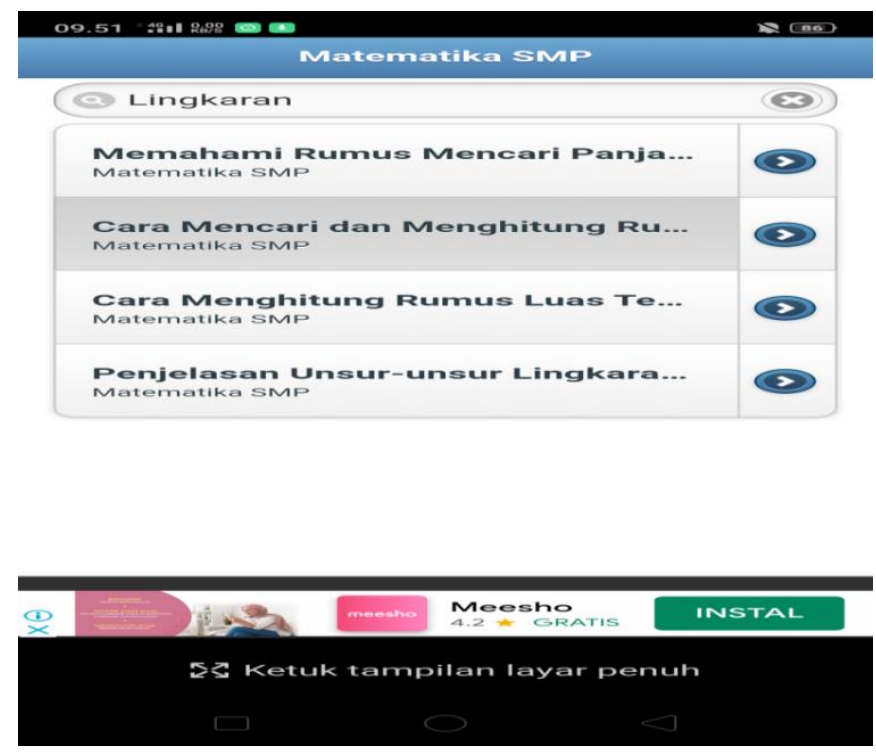

Gambar 4. Aplikasi X tentang lingkaran

Topik ke dua yang akan dibahas adalah penjumlahan bilangan bulat dan variasinya. Dalam bukunya, (Nelson, 1993) menjelaskan beberapa konsep tentang penjumlahan bilangan bulat secara visual tanpa deskripsi. Dalam penelitian ini, kita berikan beberapa contoh cara memahami penjumlahan bilangan bulat untuk siswa SMP dari gambar yang diberikan dengan menggunakan rumus luas persegi panjang pada Gambar 3.1. di atas.

Tujuan dari pembelajaran ini adalah menentukan rumus penjumlahan bilangan bulat sampai ke $n$. Pertama-tama diberikan penjumlahan bilangan bulat berturut-turut sebagai berikut:

$$
\begin{gathered}
1 \\
1+2 \\
1+2+3 \\
1+2+3+4 \\
1+2+3+4+5
\end{gathered}
$$

dan seterusnya sampai dengan penjumlahan ke $n$

$$
1+2+3+4+5+6+\cdots+n \text {. }
$$


Para siswa diajak untuk bisa menebak rumus penjumlahan tersebut. Tentunya kita belum bisa menggunakan induksi matematika untuk membuktikan rumus penjumlahan yang diperoleh. Oleh karena itu, kita lakukan simulasi atau eksperimen sederhana saja untuk menebak rumus penjumlahannya (Lihat, (Nelson, 1993)).

Perhatikan gambar berikut ini :

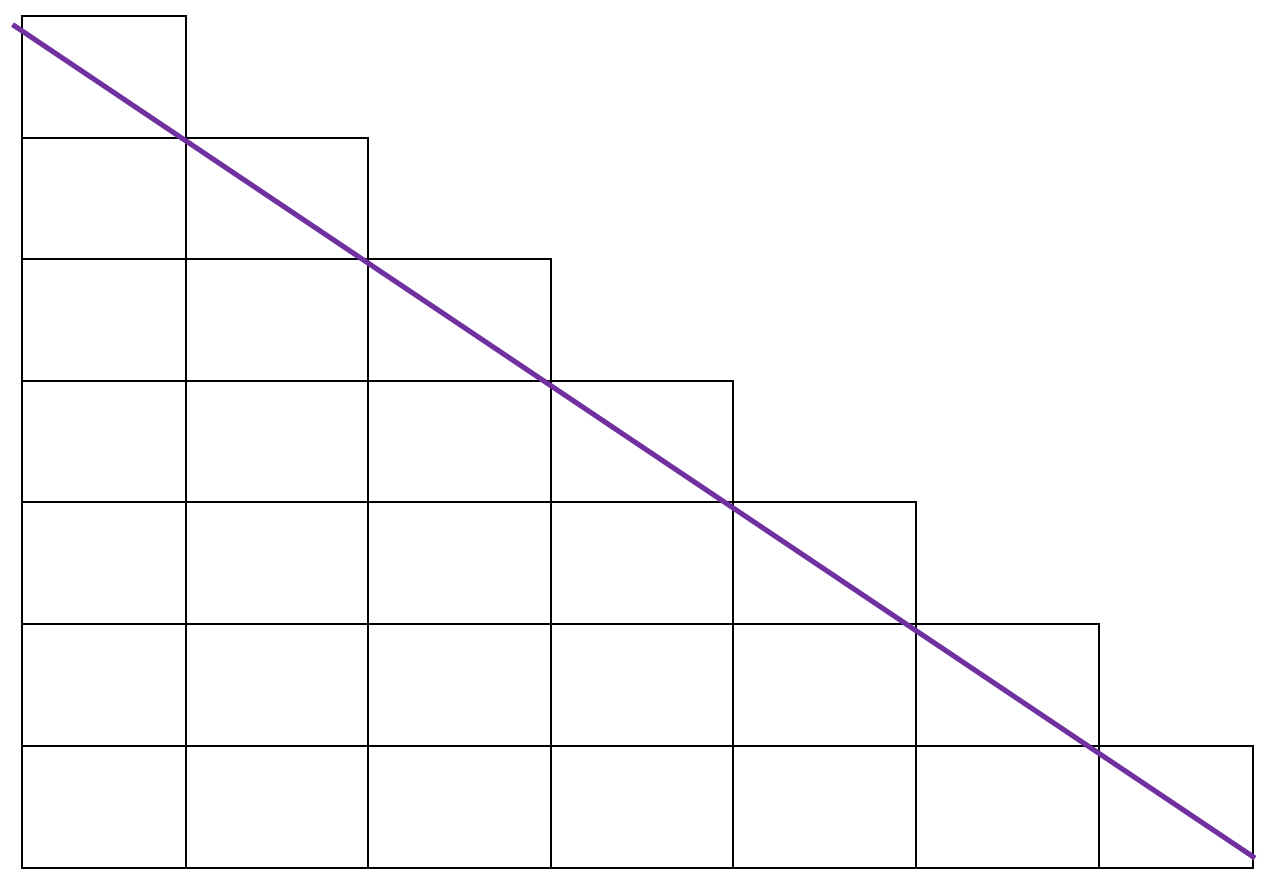

Gambar 5. Representasi $1+2+3+4+5+7$.

Misalkan setiap kotak mempunyai ukuran satu satuan. Artinya, banyak kotak yang berada di bawah garis ungu sama dengan luas segi tiga. Menggunakan Gambar 3.5. di atas, kita peroleh

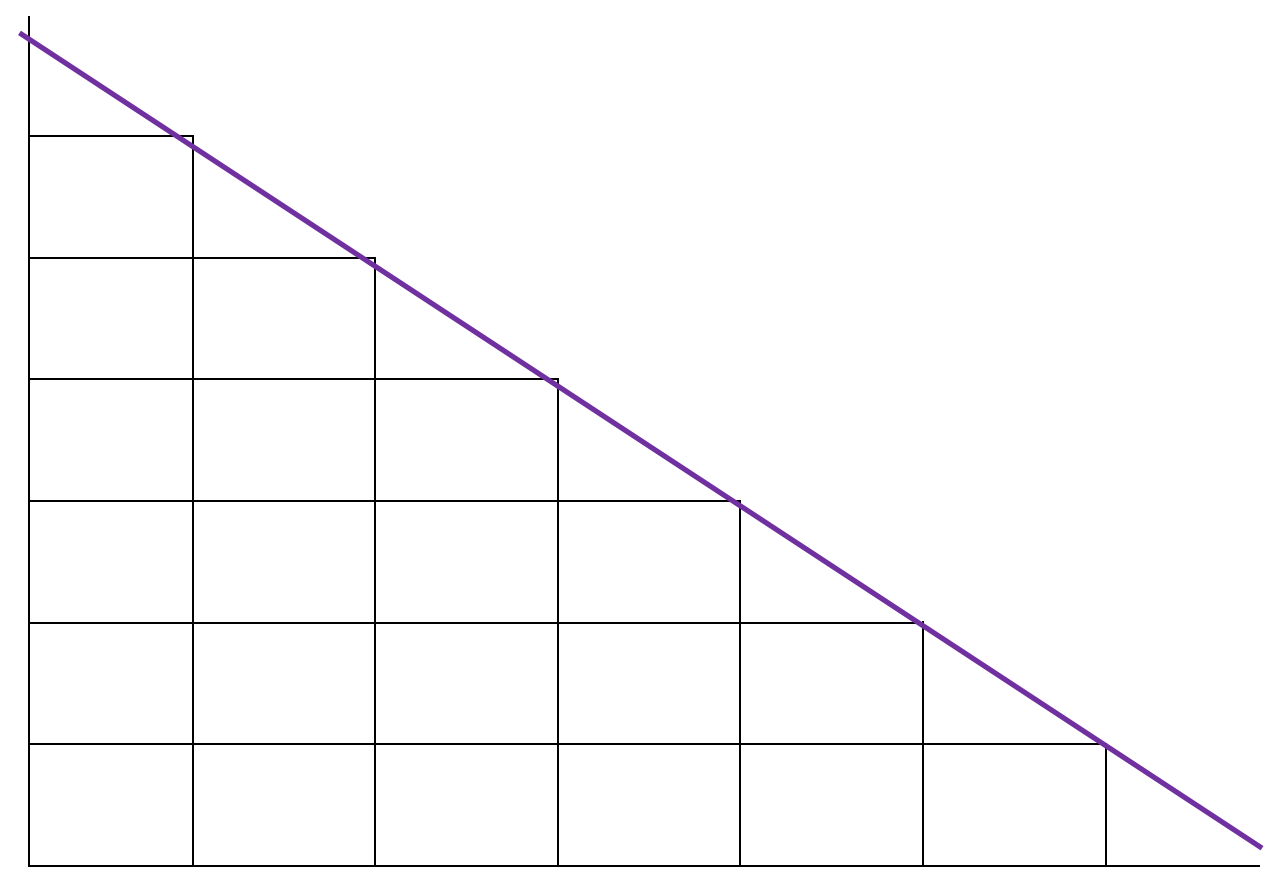

Gambar 6. Banyak kotak satuan sama dengan Luas segi tiga. 
Dari Gambar 3.6. didapat bahwa banyak kotak yang dimaksud yaitu $\frac{1}{2} \times 7 \times 7=\frac{7^{2}}{2}$. Di sisi lain, banyak kotak yang berada di atas garis ungu adalah penjumlahan seluruh setengah kotak tersebut, yaitu $\frac{7}{2}$. Dari Gambar 3.5. di atas didapat

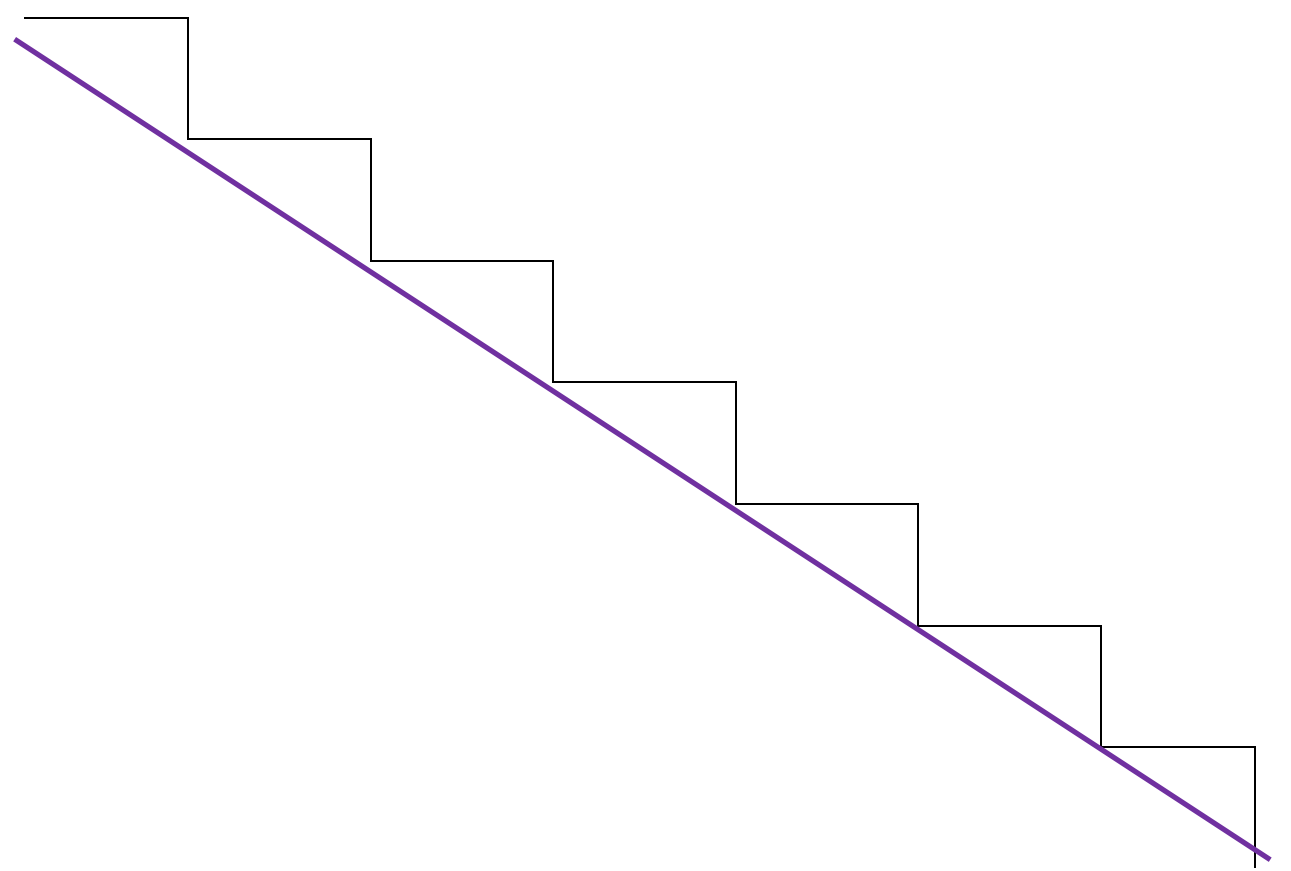

Gambar 7. Penjumlahan seluruh setengah kotak yang tersedia.

Dengan demikian, diperoleh rumusan

$$
1+2+3+4+5+6+7=\frac{7^{2}}{2}+\frac{7}{2}=28 \text {. }
$$

Selanjutnya, para siswa diajak untuk menyimulasikan untuk kasus yang berbeda dengan cara memraktikkannya dengan bantuan karton, sehingga siswa bisa merumuskan penjumlahan lain seperti

1. $1+2+3+4+5+6+7+8=\frac{8^{2}}{2}+\frac{8}{2}=36$.

2. $1+2+3+\cdots+100=\frac{100^{2}}{2}+\frac{100}{2}=5050$.

Secara umum siswa bisa menurunkan rumus umum penjumlahan bilangan bulat sebagai berikut:

$$
1+2+3+\cdots+n=\frac{n^{2}}{2}+\frac{n}{2} .
$$

Pemahaman konsep ini dapat dikembangkan dengan problem solving dari ponsel pintar masing-masing siswa.

\section{KESIMPULAN}

Pemahaman terhadap konsep matematika dapat dilakukan melalui kolaborasi antara siswa dan guru sebagai berikut (1) praktik dan simulasi permasalahan matematika yang diberikan, (2) observasi permasalahan setelah praktik dan observasi, (3) merumuskannya dalam bentuk umum, (4) pemahaman 
selanjutnya dapat dikembangkan melalui problem solving berupa penyajian soal-soal latihan dari aplikasi ponsel pintar.

\section{DAFTAR PUSTAKA}

Brown, A. (1994). The Advance of learning. Educational Researcher, 23(8), 4-12.

Fernandez, C., Chokshi, S., Cannon, J., \& Yoshida, M. (2001). Learning about lesson study in the United States. In E. Beauchamp (Ed.). New and old voices on Japanese education. New York: Sharpe.

Islamiah, N., Purwaningsih, W. E., Akbar, P., \& Bernard, M. (2018). Analisis Hubungan Kemampuan Pemecahan Masalah Matematis dan Self Confidence Siswa SMP. Journal on Education, 1(1), 47-57.

Khadijah, A., Maya, R., \& Setiawan, W. (2018). Analisis Kemampuan Komunikasi Matematis Siswa SMP Pada Materi Statistika. JPMI (Jurnal Pembelajaran Matematika Inovatif), 1(6), 1095-1104.

Lester, F. K., \& Garofalo, J. (1982). Mathematical problem solving: Issues in research. Philadelphia: The Franklin Institute Press.

Murata.A., \& Takahashi, A. (2002). Vehicle to connect theory, research, and practice: how teacher thinking changes in district-level lesson study in Japan. In proceedings of the twenty-fourth annual meeting of North American chapter of the international goup of the psychology of the mathematics education, 1879-1888.

Maharani, S., \& Bernard, M. (2018). Analisis Hubungan Resiliensi Matematik Terhadap Kemampuan Pemecahan Masalah Siswa Pada Materi Lingkaran. JPMI (Jurnal Pembelajaran Matematika Inovatif), 1(5), 819-826.

Nelson, R.B., (1993). Proofs without words : Exercuses in visual thinking. The Mathematical Association of America.

Puspitasari, E., Yusmin, E., \& Nursangaji, A. (2015). Analisis Kesulitan Siswa Menyelesaikan Soal Cerita Materi istem Persamaan Linear Dua Variabel DI SMP. Jurnal Pendidikan dan Pembelajaran, 4(5).

Sudirman, S., Cahyono, E., \& Kadir, K. (2019). Analisis Kemampuan Koneksi Matematis Siswa SMP Pesisir Ditinjau Dari Perbedaan Gender. Jurnal Pembelajaran Berpikir Matematika, 3(2).

Takahashi, A, (2006). Types of elementary mathematics lesson study in Japan. Analysis of features and characteristics. Journal of Japan Society of Mathematical Education, LXXXVIII, 25-21.

Takahashi, A, (2000). Current trends and issues in lesson study in Japan and the United States. Journal of Japan Society of Mathematical Education, 82(12), 25-21.

Yoshinori, Shimizu et al. (2015). The visual guide to mathematics, Tokyo Shoseki co, ltd, Tokyo. 